\section{An in vitro study on the compatibility and concentrations of combinations of vancomycin, amikacin, and dexamethasone in human vitreous}

M Hui', AKH Kwok ${ }^{2,3}$, CP Pang², SW Cheung1, DSC Lam² and RCY Chan'
${ }^{1}$ Department of Microbiology, The Chinese University of Hong Kong, The Prince of Wales Hospital, Hong Kong

Keywords: vancomycin; amikacin; dexamethasone; endophthalmitis

\section{Introduction}

Infective endophthalmitis is a serious condition with a potential to cause blindness. ${ }^{1}$ Owing to its urgent nature, empirical combination of antibiotics with coverage against both Grampositive and Gram-negative organisms are commonly employed. ${ }^{2,3}$ Frequently used regimens include combination of vancomycin and aminoglycosides, or vancomycin with ceftazidime. ${ }^{4,5}$ In addition, to attenuate the inflammatory response of endophthalmitis, which may be responsible for the resultant visual loss, some authorities also advocate the use of intravitreal steroid, such as dexamethasone. ${ }^{6-8}$

Although such empirical antibiotics are commonly used, their physical-chemical incompatibility was also known for many years. ${ }^{9}$ We had previously explored the precipitate formation of vancomycin and ceftazidime, ${ }^{10}$ vancomycin and ciprofloxacin. ${ }^{11}$
${ }^{2}$ Department of Ophthalmology and Visual Sciences, The Chinese University of Hong Kong, Hong Kong

${ }^{3}$ Department of Ophthalmology, The Hong Kong Sanatorium and Hospital, The Chinese University of Hong Kong, Hong Kong

Correspondence: Dr M Hui, Department of Microbiology,

The Chinese University of Hong Kong, The Prince of Wales Hospital, Hong Kong Tel: + 8522632 3333; Fax: + 85226473227

E-mail: mamiehui@ cuhk.edu.hk

Received: 20 October 2005 Accepted in revised form: 29 January 2006 Published online: 10 March 2006 
We had showed that both ceftazidime and ciprofloxacin precipitated in vitreous, with resultant reduced-free antibiotic concentration. In particular, ceftazidime concentration can fall to below the $\mathrm{MIC}_{90}$ of the drug against many commonly encountered Gram-negative organisms.

In this study, we aimed to explore the other commonly used regimen, vancomycin and amikacin, with respect to its precipitation process. In addition, we also explored the precipitation process of dexamethasone when added with vancomycin and amikacin. We investigated the process by the use of checkerboard titration and equilibrium dialysis in vitreous medium.

\section{Materials and methods}

All experiments were conducted in duplicate, and the mean values taken as results. Vitreous were obtained from cadaveric donor eyes during post-mortem examination. The vitreous obtained were immediately stored at $-70^{\circ} \mathrm{C}$ and used within 3 months. The standard intravitreal dosage of vancomycin (Abbott, Chicago, IL, USA), amikacin (Bristol-Myers Squibb, Puerto Rico, USA) and dexamethasone sodium phosphate (David Bull Laboratories, UK) for the treatment of infective endophthalmitis was $1.0,0.4$, and $0.4 \mathrm{mg}$, respectively. The medication was prepared in $0.1 \mathrm{ml}$ of $0.9 \%$ normal saline (NS) (Otsuka, Guandong, China) or balanced salt solution plus (BSS Plus, Alcon, Fort Worth, TX, USA). The vitreous volume of an adult emmetropic human eye is about $4 \mathrm{ml}$, giving respective empirical concentrations of $0.25,0.1$, and $0.1 \mathrm{mg} / \mathrm{ml}$ for vancomycin, amikacin, and dexamethasone sodium phosphate (dexamethasone) when injected into the vitreous. The actual concentration would be different, depending on the extent of precipitation and the actual vitreous volume.

\section{Assay of antibiotics}

Vancomycin and amikacin were assayed by a fluorescence polarisation immunoassay (TDx, Abbott laboratories, Diagnostic division, Abbott Park, IL, USA). Dexamethasone sodium phosphate was assayed by high-performance liquid chromatography (HPLC) as described by Kwak et $a l^{12}$ with modification of using 55: 45 mixture of methanol: water as a solvent. Its result was expressed in terms of the salt measured.

\section{Study 1: visual test}

Standard mixture solutions of $1.0 \mathrm{mg}$ vancomycin, $0.4 \mathrm{mg}$ amikacin, and $0.4 \mathrm{mg}$ dexamethasone in $0.1 \mathrm{mg}$ of $0.9 \%$ NS or BSS Plus were mixed separately with $4.0 \mathrm{ml}$ of NS, BSS Plus, and vitreous for incubation at $37^{\circ} \mathrm{C}$.

\section{Study 2: checkerboard analysis}

In the checkerboard titration study, one of the drug combinations was diluted along the rows of the microtitre plate, the other drug was diluted along the columns of the plate. Therefore, each well in the plate contains mixture of drugs at various concentrations. ${ }^{13}$ Using this technique, vancomycin, amikacin, and dexamethasone combinations were prepared in NS or BSS Plus and were incubated at $37^{\circ} \mathrm{C}$ in microtitre plates (Table 1) with cover by paraffin foil. Aliquots were taken at 24,48 , and $72 \mathrm{~h}$ for assay by HPLC (dexamethasone) and TDx (vancomycin and amikacin) to determine the concentration and amount of free drugs.

\section{Study 3: equilibrium dialysis in vitreous}

In equilibrium dialysis study, a chamber separated into two halves by a semipermeable membrane. The drugs to be assessed are injected into one side of the chamber (chamber A), it will then diffuse into the other chamber (chamber B). The time to reach equilibrium and any loss can then be assessed by measuring the drug concentrations in chamber B. ${ }^{14}$ Equilibrium dialysis studies were performed in an equilibrium dialyser (Spectrum Medical Industries, Los Angeles, CA, USA) using Teflon cells with a half cell working volume of $1.0 \mathrm{ml}$. Vancomycin $(250 \mu \mathrm{g})$, amikacin $(100 \mu \mathrm{g})$, and dexamethasone $(100 \mu \mathrm{g})$ were prepared in NS and added into half cell chamber A, which was separated from half cell chamber B by a cellulose semipermeable Spectrapor dialysis membrane with a molecular weight cutoff at

Table 1 Initial concentrations (mg/l) of (a) amikacin/vancomycin (b) dexamethasone/vancomycin, (c) dexamethasone/ amikacin prepared in microtitre plate

\begin{tabular}{rrrrr}
\hline \multicolumn{1}{l}{ (a) } & & & & \\
$0 / 0$ & $0 / 250$ & $0 / 125$ & $0 / 62.5$ & $0 / 31.25$ \\
$100 / 0$ & $100 / 250$ & $100 / 125$ & $100 / 62.5$ & $100 / 31.25$ \\
$50 / 0$ & $50 / 250$ & $50 / 125$ & $50 / 62.5$ & $50 / 31.25$ \\
$25 / 0$ & $25 / 250$ & $25 / 125$ & $25 / 62.5$ & $25 / 31.25$ \\
$12.5 / 0$ & $12.5 / 250$ & $12.5 / 125$ & $12.5 / 62.5$ & $12.5 / 31.25$ \\
& & & & \\
(b) & & & & \\
$0 / 0$ & $0 / 250$ & $0 / 125$ & $0 / 62.5$ & $0 / 31.25$ \\
$100 / 0$ & $100 / 250$ & $100 / 125$ & $100 / 62.5$ & $100 / 31.25$ \\
$50 / 0$ & $50 / 250$ & $50 / 125$ & $50 / 62.5$ & $50 / 31.25$ \\
$25 / 0$ & $25 / 250$ & $25 / 125$ & $25 / 62.5$ & $25 / 31.25$ \\
$12.5 / 0$ & $12.5 / 250$ & $12.5 / 125$ & $12.5 / 62.5$ & $12.5 / 31.25$ \\
& & & & \\
(c) & & & & \\
$0 / 0$ & $0 / 100$ & $0 / 50$ & $0 / 25$ & $0 / 12.5$ \\
$100 / 0$ & $100 / 100$ & $100 / 50$ & $100 / 25$ & $100 / 12.5$ \\
$50 / 0$ & $50 / 100$ & $50 / 50$ & $50 / 25$ & $50 / 12.5$ \\
$25 / 0$ & $25 / 100$ & $25 / 50$ & $25 / 25$ & $25 / 12.5$ \\
$12.5 / 0$ & $12.5 / 100$ & $12.5 / 50$ & $12.5 / 25$ & $12.5 / 12.5$ \\
\hline
\end{tabular}


6000-8000 D (Spectrum Medical Industries). Both chambers were filled with $1.0 \mathrm{ml}$ of vitreous. The whole system was incubated at $37^{\circ} \mathrm{C}$ Aliquots were taken from half cell chamber B at appropriate time intervals up to $192 \mathrm{~h}$ for drug assay. The experiment was then repeated with the drugs prepared in BSS Plus.

\section{Results}

\section{Study 1: visual test}

Precipitate was not visually detected in NS, BSS Plus, and vitreous after incubation for 1 day at $37^{\circ} \mathrm{C}$.

\section{Study 2: checkerboard analysis in microtitre plates}

Amikacin alone showed no measurable loss in NS or BSS Plus up to $72 \mathrm{~h}$ of incubation (first rows, Tables $2 \mathrm{~g}-\mathrm{l}$ ). Vancomycin alone in NS showed no measurable loss up to $72 \mathrm{~h}$ of incubation (first rows, Tables $2 \mathrm{a}-\mathrm{c}$ ). While in BSS Plus, vancomycin alone showed minimal loss (median $0 \%$, first rows, Tables $2 \mathrm{~d}-\mathrm{f}$ ).

Dexamethasone alone in NS showed measurable decrease of $0-12 \%$ (median $5 \%$ ) after $24 \mathrm{~h}$ of incubation.

Table 2 (a) Percentage loss of dexamethasone/vancomycin after (a) $24 \mathrm{~h}$ in NS (b) $48 \mathrm{~h}$ in NS (c) $72 \mathrm{~h}$ in NS (d) $24 \mathrm{~h}$ in BSS Plus (e) $48 \mathrm{~h}$ in BSS Plus (f) $72 \mathrm{~h}$ in BSS Plus. Percentage loss of dexamethasone/amikacin after (g) $24 \mathrm{~h}$ in NS (h) $48 \mathrm{~h}$ in NS (i) $72 \mathrm{~h}$ in NS (j) $24 \mathrm{~h}$ in BSS Plus (k) $48 \mathrm{~h}$ in BSS Plus (l) $72 \mathrm{~h}$ in BSS Plus

\begin{tabular}{|c|c|c|c|c|}
\hline \multicolumn{5}{|l|}{ (a) } \\
\hline $0^{\mathrm{a}} / 0^{\mathrm{a}}$ & $0^{\mathrm{a}} / 0^{\mathrm{a}}$ & $0^{\mathrm{a}} / 0^{\mathrm{a}}$ & $0^{\mathrm{a}} / 0^{\mathrm{a}}$ & $0^{\mathrm{a}} / 0^{\mathrm{a}}$ \\
\hline $3 / 0^{a}$ & $7 / 0^{\mathrm{a}}$ & $5 / 0^{\mathrm{a}}$ & $5 / 0^{\mathrm{a}}$ & $5 / 0^{a}$ \\
\hline $9 / 0^{a}$ & $9 / 0^{a}$ & $11 / 0^{a}$ & $11 / 0^{\mathrm{a}}$ & $12 / 0^{a}$ \\
\hline $2 / 0^{a}$ & $3 / 0^{a}$ & $6 / 0^{a}$ & $4 / 0^{a}$ & $7 / 0^{a}$ \\
\hline $0^{a} / 0^{a}$ & $0^{\mathrm{a}} / 0^{\mathrm{a}}$ & $0^{\mathrm{a}} / 0^{\mathrm{a}}$ & $0^{\mathrm{a}} / 0^{\mathrm{a}}$ & $0^{\mathrm{a}} / 0^{\mathrm{a}}$ \\
\hline \multicolumn{5}{|l|}{ (b) } \\
\hline $0^{\mathrm{a}} / 0^{\mathrm{a}}$ & $0^{\mathrm{a}} / 0^{\mathrm{a}}$ & $0^{\mathrm{a}} / 0^{\mathrm{a}}$ & $0^{\mathrm{a}} / 0^{\mathrm{a}}$ & $0^{\mathrm{a}} / 0^{\mathrm{a}}$ \\
\hline $11 / 0^{a}$ & $10 / 0^{a}$ & $12 / 0^{a}$ & $11 / 0^{\mathrm{a}}$ & $8 / 0^{a}$ \\
\hline $12 / 0^{a}$ & $13 / 0^{a}$ & $13 / 0^{a}$ & $10 / 0^{\mathrm{a}}$ & $12 / 0^{a}$ \\
\hline $25 / 0^{a}$ & $24 / 0^{a}$ & $25 / 0^{a}$ & $25 / 0^{a}$ & $24 / 0^{a}$ \\
\hline $20 / 0^{a}$ & $35 / 0^{a}$ & $37 / 0^{a}$ & $32 / 0^{a}$ & $34 / 0^{a}$ \\
\hline \multicolumn{5}{|l|}{ (c) } \\
\hline $0^{a} / 0^{a}$ & $0^{\mathrm{a}} / 0^{\mathrm{a}}$ & $0^{\mathrm{a}} / 0^{\mathrm{a}}$ & $0^{\mathrm{a}} / 0^{\mathrm{a}}$ & $0^{\mathrm{a}} / 0^{\mathrm{a}}$ \\
\hline $9 / 0^{a}$ & $9 / 0^{a}$ & $4 / 0^{\mathrm{a}}$ & $8 / 0^{\mathrm{a}}$ & $4 / 0^{\mathrm{a}}$ \\
\hline $4 / 0^{a}$ & $7 / 0^{\mathrm{a}}$ & $6 / 0^{\mathrm{a}}$ & $9 / 0^{\mathrm{a}}$ & $7 / 0^{a}$ \\
\hline $26 / 0^{a}$ & $22 / 0^{a}$ & $21 / 0^{a}$ & $23 / 0^{a}$ & $23 / 0^{a}$ \\
\hline $16 / 0^{a}$ & $12 / 0^{a}$ & $8 / 0^{\mathrm{a}}$ & $0^{\mathrm{a}} / 0^{\mathrm{a}}$ & $10 / 0^{a}$ \\
\hline \multicolumn{5}{|l|}{ (d) } \\
\hline $0^{\mathrm{a}} / 0^{\mathrm{a}}$ & $0^{\mathrm{a}} / 0^{\mathrm{a}}$ & $0^{\mathrm{a}} / 0^{\mathrm{a}}$ & $0^{\mathrm{a}} / 0^{\mathrm{a}}$ & $0^{\mathrm{a}} / 0^{\mathrm{a}}$ \\
\hline $8 / 0^{a}$ & $5 / 0^{a}$ & $5 / 0^{a}$ & $16 / 0^{\mathrm{a}}$ & $12 / 0^{a}$ \\
\hline $8 / 0^{a}$ & $8 / 0^{\mathrm{a}}$ & $10 / 0^{\mathrm{a}}$ & $9 / 0^{a}$ & $10 / 0^{\mathrm{a}}$ \\
\hline $16 / 0^{a}$ & $13 / 0^{a}$ & $13 / 0^{\mathrm{a}}$ & $13 / 0^{\mathrm{a}}$ & $14 / 0^{a}$ \\
\hline $18 / 0^{a}$ & $27 / 0^{a}$ & $27 / 0^{a}$ & $30 / 0^{a}$ & $26 / 0^{a}$ \\
\hline
\end{tabular}

Table 2 (Continued)

(e)

$\begin{array}{ccccc}0^{\mathrm{a}} / 0^{\mathrm{a}} & 0^{\mathrm{a}} / 0^{\mathrm{a}} & 0^{\mathrm{a}} / 0^{\mathrm{a}} & 0^{\mathrm{a}} / 0^{\mathrm{a}} & 0^{\mathrm{a}} / 0^{\mathrm{a}} \\ 24 / 0^{\mathrm{a}} & 22 / 0^{\mathrm{a}} & 22 / 0^{\mathrm{a}} & 24 / 0^{\mathrm{a}} & 22 / 0^{\mathrm{a}} \\ 11 / 0^{\mathrm{a}} & 10 / 0^{\mathrm{a}} & 10 / 0^{\mathrm{a}} & 13 / 0^{\mathrm{a}} & 12 / 0^{\mathrm{a}} \\ 14 / 0^{\mathrm{a}} & 14 / 0^{\mathrm{a}} & 13 / 0^{\mathrm{a}} & 12 / 0^{\mathrm{a}} & 12 / 0^{\mathrm{a}} \\ 29 / 0^{\mathrm{a}} & 32 / 0^{\mathrm{a}} & 33 / 0^{\mathrm{a}} & 30 / 0^{\mathrm{a}} & 32 / 0^{\mathrm{a}} \\ & & & & \\ (\mathbf{f}) & & & & \\ 0^{\mathrm{a}} / 0^{\mathrm{a}} & 0^{\mathrm{a}} / 5 & 0^{\mathrm{a}} / 0^{\mathrm{a}} & 0^{\mathrm{a}} / 0^{\mathrm{a}} & 0^{\mathrm{a}} / 0^{\mathrm{a}} \\ 20 / 0^{\mathrm{a}} & 16 / 0^{\mathrm{a}} & 17 / 0^{\mathrm{a}} & 21 / 2 & 17 / 0^{\mathrm{a}} \\ 10 / 0^{\mathrm{a}} & 10 / 4 & 11 / 0^{\mathrm{a}} & 8 / 0^{\mathrm{a}} & 4 / 0^{\mathrm{a}} \\ 9 / 0^{\mathrm{a}} & 10 / 0^{\mathrm{a}} & 6 / 0^{\mathrm{a}} & 10 / 3 & 11 / 0^{\mathrm{a}} \\ 0^{\mathrm{a}} / 0^{\mathrm{a}} & 0^{\mathrm{a}} / 0^{\mathrm{a}} & 3 / 0^{\mathrm{a}} & 1 / 0 & 3 / 0^{\mathrm{a}}\end{array}$

(g)

$0^{\mathrm{a}} / 0^{\mathrm{a}}$

$12 / 0^{\mathrm{a}}$

$7 / 0^{\mathrm{a}}$

$8 / 0^{\mathrm{a}}$

$0^{\mathrm{a}} / 0^{\mathrm{a}}$

$$
\begin{array}{r}
0^{\mathrm{a}} / 0^{\mathrm{a}} \\
8 / 0^{\mathrm{a}} \\
8 / 0^{\mathrm{a}} \\
10 / 0^{\mathrm{a}} \\
1 / 0^{\mathrm{a}}
\end{array}
$$

$$
\begin{array}{r}
0^{\mathrm{a}} / 0^{\mathrm{a}} \\
8 / 0^{\mathrm{a}} \\
13 / 0^{\mathrm{a}} \\
6 / 0^{\mathrm{a}} \\
3 / 0^{\mathrm{a}}
\end{array}
$$

$0^{\mathrm{a}} / 0^{\mathrm{a}}$
$10 / 0^{\mathrm{a}}$
$9 / 0^{\mathrm{a}}$
$10 / 0^{\mathrm{a}}$
$6 / 0^{\mathrm{a}}$

$0^{\mathrm{a}} / 0^{\mathrm{a}}$

$10 / 0^{\mathrm{a}}$

$10 / 0^{\mathrm{a}}$

$9 / 0^{\mathrm{a}}$

$4 / 0^{\mathrm{a}}$

(h)

$\begin{array}{rrrrr}0^{\mathrm{a}} / 0^{\mathrm{a}} & 0^{\mathrm{a}} / 0^{\mathrm{a}} & 0^{\mathrm{a}} / 0^{\mathrm{a}} & 0^{\mathrm{a}} / 0^{\mathrm{a}} & 0^{\mathrm{a}} / 0^{\mathrm{a}} \\ 5 / 0^{\mathrm{a}} & 7 / 0^{\mathrm{a}} & 5 / 0^{\mathrm{a}} & 6 / 0^{\mathrm{a}} & 6 / 0^{\mathrm{a}} \\ 6 / 0^{\mathrm{a}} & 3 / 0^{\mathrm{a}} & 7 / 0^{\mathrm{a}} & 7 / 0^{\mathrm{a}} & 2 / 0^{\mathrm{a}} \\ 22 / 0^{\mathrm{a}} & 24 / 0^{\mathrm{a}} & 24 / 0^{\mathrm{a}} & 21 / 0^{\mathrm{a}} & 21 / 0^{\mathrm{a}} \\ 21 / 0^{\mathrm{a}} & 28 / 0^{\mathrm{a}} & 20 / 0^{\mathrm{a}} & 23 / 0^{\mathrm{a}} & 22 / 0^{\mathrm{a}}\end{array}$

(i)

$0^{\mathrm{a}} / 0^{\mathrm{a}}$

$8 / 0^{\mathrm{a}}$

$13 / 0^{a}$

$22 / 0^{\mathrm{a}}$

$18 / 0^{\mathrm{a}}$

$0^{\mathrm{a}} / 0^{\mathrm{a}}$

$5 / 0^{\mathrm{a}}$

$13 / 0^{\mathrm{a}}$

$24 / 0^{\mathrm{a}}$

$18 / 0^{\mathrm{a}}$

$0^{\mathrm{a}} / 0^{\mathrm{a}}$

$7 / 0^{\mathrm{a}}$

$8 / 0^{a}$

$25 / 0^{\mathrm{a}}$

$18 / 0^{a}$

$0^{\mathrm{a}} / 0^{\mathrm{a}}$

$9 / 0^{a}$

$10 / 0^{\mathrm{a}}$

$23 / 0^{a}$

$18 / 0^{a}$

$0^{\mathrm{a}} / 0^{\mathrm{a}}$

$8 / 0^{\mathrm{a}}$

$10 / 0^{a}$

$20 / 0^{a}$

$19 / 0^{\mathrm{a}}$

(j)

$0^{\mathrm{a}} / 0^{\mathrm{a}}$

$16 / 0^{a}$

$4 / 0^{\mathrm{a}}$

$14 / 0^{a}$

$0^{\mathrm{a}} / 0^{\mathrm{a}}$

$0^{\mathrm{a}} / 0^{\mathrm{a}}$
$18 / 0^{\mathrm{a}}$
$9 / 0^{\mathrm{a}}$
$14 / 0^{\mathrm{a}}$
$0^{\mathrm{a}} / 0^{\mathrm{a}}$

$0^{\mathrm{a}} / 0^{\mathrm{a}}$

$18 / 0^{\mathrm{a}}$

$8 / 0^{\mathrm{a}}$

$12 / 0^{\mathrm{a}}$

$0^{\mathrm{a}} / 0^{\mathrm{a}}$

$0^{\mathrm{a}} / 0^{\mathrm{a}}$

$16 / 0^{\mathrm{a}}$

$6 / 0^{\mathrm{a}}$

$14 / 0^{\mathrm{a}}$

$2 / 0^{\mathrm{a}}$

$0^{\mathrm{a}} / 0^{\mathrm{a}}$

$17 / 0^{\mathrm{a}}$

$4 / 0^{\mathrm{a}}$

$8 / 0^{a}$

$14 / 0^{a}$

(k)

$0^{\mathrm{a}} / 0^{\mathrm{a}}$

$17 / 0^{a}$

$8 / 0^{\mathrm{a}}$

$11 / 0^{a}$

$0^{\mathrm{a}} / 0^{\mathrm{a}}$

$17 / 0^{\mathrm{a}}$

$6 / 0^{\mathrm{a}}$

$12 / 0^{\mathrm{a}}$

$0^{\mathrm{a}} / 0^{\mathrm{a}}$

$12 / 0^{\mathrm{a}}$

$8 / 0^{\mathrm{a}}$

$10 / 0^{\mathrm{a}}$

$18 / 0^{\mathrm{a}}$

$0^{\mathrm{a}} / 0^{\mathrm{a}}$

$12 / 0^{\mathrm{a}}$

$6 / 0^{\mathrm{a}}$

$5 / 0^{\mathrm{a}}$

$17 / 0^{a}$

$0^{\mathrm{a}} / 0^{\mathrm{a}}$

$14 / 0^{\mathrm{a}}$

$8 / 0^{a}$

$10 / 0^{a}$

$20 / 0^{a}$

(1)

\begin{tabular}{lllrr}
$0^{\mathrm{a}} / 0^{\mathrm{a}}$ & $0^{\mathrm{a}} / 0^{\mathrm{a}}$ & $0^{\mathrm{a}} / 0^{\mathrm{a}}$ & $0^{\mathrm{a}} / 0^{\mathrm{a}}$ & $0^{\mathrm{a}} / 0^{\mathrm{a}}$ \\
$18 / 0^{\mathrm{a}}$ & $23 / 0^{\mathrm{a}}$ & $21 / 0^{\mathrm{a}}$ & $23 / 0^{\mathrm{a}}$ & $25 / 0^{\mathrm{a}}$ \\
$10 / 0^{\mathrm{a}}$ & $10 / 0^{\mathrm{a}}$ & $12 / 0^{\mathrm{a}}$ & $11 / 0^{\mathrm{a}}$ & $13 / 0^{\mathrm{a}}$ \\
$14 / 0^{\mathrm{a}}$ & $12 / 0^{\mathrm{a}}$ & $13 / 0^{\mathrm{a}}$ & $6 / 0^{\mathrm{a}}$ & $13 / 0^{\mathrm{a}}$ \\
$0^{\mathrm{a}} / 0^{\mathrm{a}}$ & $14 / 0^{\mathrm{a}}$ & $0^{\mathrm{a}} / 0^{\mathrm{a}}$ & $8 / 0^{\mathrm{a}}$ & $8 / 0^{\mathrm{a}}$ \\
\hline
\end{tabular}

${ }^{\mathrm{a}}$ No measurable loss.

After $48 \mathrm{~h}$, its concentration decreased by $5-25 \%$, (median 16\%). At $72 \mathrm{~h}$, the loss was $4-26 \%$, median $14 \%$ (first columns, Tables $2 \mathrm{a}-\mathrm{c}, \mathrm{g}-\mathrm{l}$ ). While in BSS Plus, it 
showed a decrease of $0-18 \%$ (median $11 \%$ ) at $24 \mathrm{~h}$ of incubation. The decrease was $8-29 \%$ (median 15\%) at $48 \mathrm{~h}$. At $72 \mathrm{~h}$, the decrease was $0-20 \%$, median $10 \%$ (first columns, Tables $2 \mathrm{~d}-\mathrm{f}, \mathrm{j}-\mathrm{l})$. There was no statistically significant difference in dexamethasone concentration when incubated alone in NS or BSS Plus (Student's $t$ test, $P>0.05)$.

In mixture of amikacin and vancomycin, there was no measurable loss of amikacin in NS or BSS Plus up to $72 \mathrm{~h}$ of incubation. For vancomycin, it showed no loss in this mixture for up to $72 \mathrm{~h}$ of incubation in NS. In BSS Plus, it showed minimal loss with median $0 \%$ (results not shown). For mixture of dexamethasone and vancomycin, vancomycin again showed no measurable loss in NS up to $72 \mathrm{~h}$. It showed a loss of 0-4\% (median 0\%) in BSS Plus. Dexamethasone showed loss in NS of 0-37\% (median 9\%). Its loss was $0-33 \%$, median $13 \%$ in BSS Plus (Tables 2a-f). For mixture of dexamethasone and amikacin, amikacin showed no measurable loss in NS or BSS Plus up to $72 \mathrm{~h}$. Dexamethasone loss was 1-28\%, median $10 \%$ in NS. While in BSS Plus, dexamethasone loss was $0-25 \%$, median $12 \%$ (Tables $2 \mathrm{~g}-1$ ). There was no statistically significant difference in the loss of dexamethasone when it was incubated with amikacin or vancomycin, or when incubated in NS or BSS Plus (Student's $t$ test, $P>0.05$ ).

\section{Study 3: equilibrium dialysis in vitreous}

The drugs were prepared in NS and injected into dialysis chamber A which was filled with vitreous. The vancomycin concentration in chamber $\mathrm{B}$ rose to about $44 \%$ of its original concentration in chamber A after about $24 \mathrm{~h}$ and then plateau off. Its concentration was able to maintain to about $40 \%$ of its original concentration at the end of the experiment at $192 \mathrm{~h}$. For Amikacin, it rose to about $50 \%$ at $5 \mathrm{~h}$, and then plateau off. For dexamethasone, it rose to about $45 \%$ at $12 \mathrm{~h}$, it then fluctuated slightly but maintaining at about $50 \%$ till the end of the experiment. This experiment was repeated with the drugs prepared in BSS Plus and it showed similar results (Figures 1 and 2).

\section{Discussion}

The use of combination intravitreal antibiotics is widely employed in the treatment of endophthalmitis. It is also known to ophthalmologist that precipitation can occur
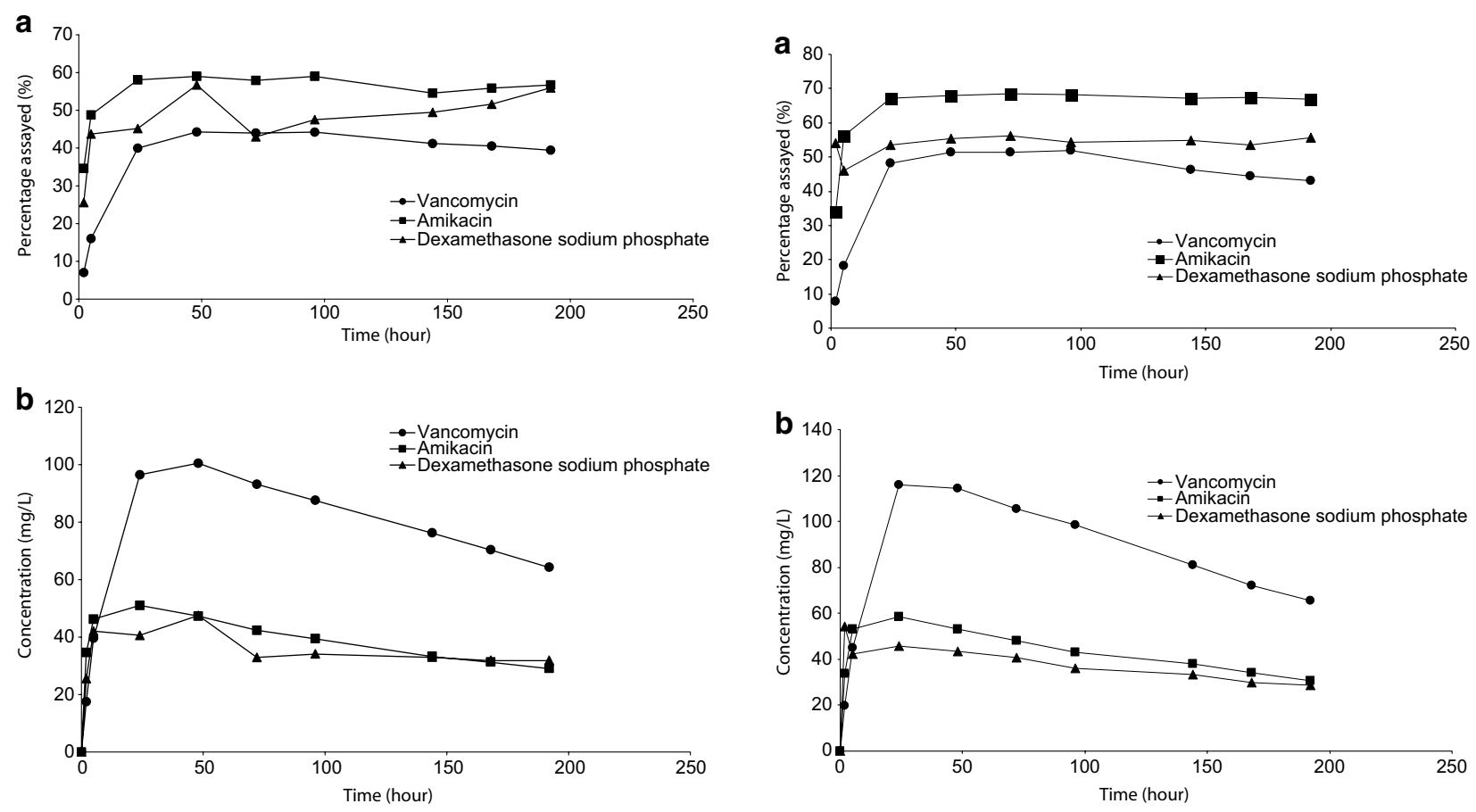

Figure 1 (a) Equilibirum dialysis in vitreous medium with vancomycin, amikacin, and dexamethasone sodium phosphate initially prepared in normal saline. Percentage change in concentration in vitreous of chamber B. (b) Equilibirum dialysis in vitreous medium with vancomycin, amikacin, and dexamethasone sodium phosphate initially prepared in normal saline. Actual change in concentration in vitreous of chamber B.

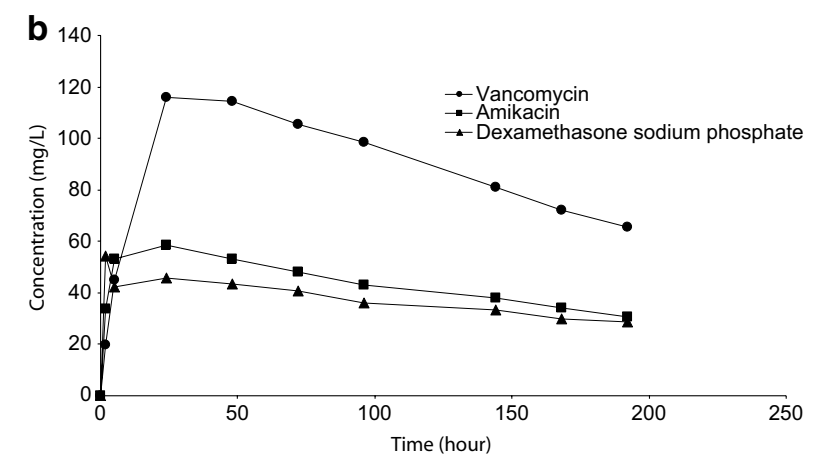

Figure 2 (a) Equilibirum dialysis in vitreous medium with vancomycin, amikacin, and dexamethasone sodium phosphate initially prepared in BSS Plus. Percentage change in concentration in vitreous of chamber B. (b) Equilibirum dialysis in vitreous medium with vancomycin, amikacin, and dexamethasone sodium phosphate initially prepared in BSS Plus. Actual change in concentration in vitreous of chamber B. 
with the mixing of vancomycin and ceftazidime. ${ }^{15} \mathrm{We}$ had previously explored this process by the use of checkerboard analysis and equilibrium dialysis, and showed that both ceftazidime and ciprofloxacin precipitated to various extent in vitreous, and the precipitation can be affected by $\mathrm{pH}$, temperature and choice of preparation medium (NS or BSS Plus).

In this study, we explored the possible precipitation process of another commonly used antibiotic regimen in the treatment of endophthalmitis: vancomycin and amikacin, as well as the anti-inflammatory agent dexamethasone. Fluorescence polarisation immunoassay (TDx) is used for the measurement for vancomycin and amikacin. Its precision and accuracy had been previously validated and employed in other ophthalmic study. ${ }^{16-18}$ Dexamethasone assay was performed by HPLC as validated by Kwak et al. ${ }^{12}$ The accuracy of the TDx and HPLC was ascertained by preliminary studies using known concentrations of vancomycin, amikacin, dexamethasone, as well as internal quality controls (data not shown).

In the checkerboard study, vancomycin had showed no loss in NS, either alone or in combination with amikacin or dexamethasone. It showed minimal loss when incubated in BSS Plus, also either alone or when in combination with amikacin or dexamethasone. This finding is consistent with our previous experiment, which also showed that vancomycin showed minimal loss when combined with ceftazidime or ciprofloxacin. This result suggests that vancomycin appears to be a stable chemical, and is capable of maintaining its free concentration despite the variety of media and combination of drugs being used.

Previous investigators had explored the effects on elimination of intravitreal vancomycin by intravitreal dexamethasone. However, animal experimental models with Streptococcus pneumoniae and Staphylococcus epidermidis had yielded conflicting results. ${ }^{19,20}$ As our in vitro study suggests that loss of vancomycin was minimal, either alone or in the presence of other medications or media, other in vivo variations, such as organism characteristics, host inflammatory response and breakdown of blood-ocular barrier, may account for the opposite results obtained by previous in vivo studies. Smith et $a l^{19}$ had suggested that the elimination of vancomycin through the canal of Schlemm may be facilitated by the presence of steroids, resulting in lower intraocular levels. However, as S. epidermidis is an organism of low virulence, as opposed to the $S$.

pneumoniae used by Park et al, the degree of inflammation and the resultant effect of steroids may well be different. As suggested by Park et al, the beneficial effect of steroids in reducing blood-ocular barrier breakdown may have greater impact than the enhancement of elimination of antibiotic. To further address the effect of steroids, further in vivo studies are warranted.

Amikacin also showed no measurable loss in the checkerboard study, whether it was in NS or BSS Plus, alone or in combination with vancomycin or dexamethasone. This appears extraordinary as other anti-Gram-negatives antibiotics previously tested, such as ceftazidime and ciprofloxacin, showed precipitation to various extent. This is of further interest as BSS Plus, with its advantages of containing appropriate bicarbonate, $\mathrm{pH}$, ions, and glutathione, is preferred over NS for intravitreal irrigation for its ability to maintain retinal electrical activity and endothelial cell adenosine triphosphate. BSS Plus, however, increases the precipitation of ceftazidime. ${ }^{9}$ Therefore, amikacin would appear to be the most stable antibiotic tested so far, with its free drug concentration maintained adequately and not affected by the medium of preparation. This would also suggest that amikacin is preferred over ceftazidime or ciprofloxacin for its lack of precipitation and resultant loss of free drug.

Dexamethasone showed measurable loss when alone or in combination, in NS or BSS Plus. The precipitation process and the loss in free drug appeared independent of the medium used, and was not affected mixing with amikacin or vancomycin, as shown by the insignificant Student's $t$ test results. The medians of decrease in dexamethasone concentration ranged from 5 to $16 \%$ in this checkerboard study. It had been suggested that rabbit fibroblast proliferation can be inhibited by dexamethasone at $200 \mu \mathrm{g} / \mathrm{ml}^{21}$ However, whether this loss in the current study can contribute to clinical failure would require further studies.

In the equilibrium dialysis study, vancomycin, amikacin, and dexamethasone all distributed readily and evenly into the two dialysis chamber. Amikacin was the fastest to reach equilibrium by $5 \mathrm{~h}$. Vancomycin, as in previous study, reached equilibrium at about $24 \mathrm{~h}$. Dexamethasone reached equilibrium at about $12 \mathrm{~h}$. All three drugs maintain their concentrations till the end of the experiment. There was no difference observed when the drugs were prepared in NS or BSS Plus. The results of this suggest that the combination regimen of vancomycin and amikacin is currently the most stable drugs when tested in our experiments. Adequate free drug concentration can be maintained, and was not affected by the choice of preparation medium of either NS or BSS Plus. Importantly, the antibiotics level should be higher than the $\mathrm{MIC}_{90}$ of commonly encountered pathogens. ${ }^{10}$ Dexamethasone, although its use is controversial, ${ }^{22,23}$ also exhibited favourable pharmacokinetic profiles with small percentage loss only. Nonetheless, this loss should be taken into account when designing the intravitreal dosage for this medication. 
With the limited number of antibiotics that can be used intravitrealy, and the significant antibiotic loss with precipitation, the vancomycin-amikacin regimen would be the preferred choice in the treatment of infective endophthalmitis.

\section{Acknowledgements}

This research was financially supported by block grant to the Chinese University of Hong Kong.

\section{References}

1 Shrader SK, Band JD, Lauter CB, Murphy P. The clinical spectrum of endophthalmitis: incidence, predisposing factors, and features influencing outcome. J Infect Dis 1990; 162: $115-120$.

2 Kunimoto DY, Das T, Sharma S, Jalali S, Majji AB, Gopinathan $\mathrm{U}$ et al. Microbiologic spectrum and susceptibility of isolates: part I. Postoperative endophthalmitis. Endophthalmitis Research Group. Am J Ophthalmol 1999; 128: 240-242.

3 Kunimoto DY, Das T, Sharma S, Jalali S, Majji AB, Gopinathan $\mathrm{U}$ et al. Microbiologic spectrum and susceptibility of isolates: Part II. Posttraumatic endophthalmitis. Endophthalmitis Research Group. Am J Ophthalmol 1999; 128: 242-244.

4 Benz MS, Scott IU, Flynn Jr HW, Unonius N, Miller D. Endophthalmitis isolates and antibiotic sensitivities: a 6-year review of culture-proven cases. Am J Ophthalmol 2004; 137: 38-42.

5 Yam JC, Kwok AK. Update of the management of postoperative endophthalmitis. Hong Kong Med J 2004; 10: 337-343.

6 Park SS, Samiy N, Ruoff K, D'Amico DJ, Baker AS. Effect of intravitreal dexamethasone in treatment of pneumococcal endophthalmitis in rabbits. Arch Ophthalmol 1995; 113: 1324-1329.

7 Das T, Jalali S, Gothwal VK, Sharma S, Naduvilath TJ. Intravitreal dexamethasone in exogenous bacterial endophthalmitis: results of a prospective randomised study. Br J Ophthalmol 1999; 83: 1050-1055.

8 Yoshizumi MO, Bhavsar AR, Dessouki A, Kashani A. Safety of repeated intravitreous injections of antibiotics and dexamethasone. Retina 1999; 19: 437-441.

9 Fiscella RG. Physical incompatibility of vancomycin and ceftazidime for intravitreal injection. Arch Ophthalmol 1993; 111: 730.

10 Kwok AK, Hui M, Pang CP, Chan RC, Cheung SW, Yip CM et al. An in vitro study of ceftazidime and vancomycin concentrations in various fluid media: implications for use in treating endophthalmitis. Invest Ophthalmol Vis Sci 2002; 43: 1182-1188.

11 Hui M, Kwok AK, Pang CP, Cheung SW, Chan RC, Lam DS et al. An in vitro study on the compatibility and precipitation of a combination of ciprofloxacin and vancomycin in human vitreous. Br J Ophthalmol 2004; 88: 218-222.

12 Kwak HW, D'Amico DJ. Determination of dexamethasone sodium phosphate in the vitreous by high performance liquid chromatography. Korean J Ophthalmol 1995; 9: 79-83.

13 Eliopoulos GM, Moellering RC. Antimicrobial combinations. In: Lorian V (ed). Antibiotics in Laboratory Medicine. Williams \& Wilkins: Baltimore, 1996, pp 333.

14 Barre J, Chamouard JM, Houlin G, Tillement JP. Equilibrium dialysis, ultrafiltration, and ultracentrifugation compared for determining the plasma-protein-binding characteristics of valproic acid. Clin Chem 1985; 31: 60-64

15 Lifshitz T, Lapid-Gortzak R, Finkelman Y, Klemperer I. Vancomycin and ceftazidime incompatibility upon intravitreal injection. Br J Ophthalmol 2000; 84: 117-118.

16 Pfaller MA, Krogstad DJ, Granich GG, Murray PR. Laboratory evaluation of five assay methods for vancomycin: bioassay, high-pressure liquid chromatography, fluorescence polarization immunoassay, radioimmunoassay, and fluorescence immunoassay. J Clin Microbiol 1984; 20: 311-316.

17 Ngui-yen JH, Doyle PW, Smith JA. Comparative analysis of two rapid, automated methods for determining aminoglycosides levels. J Clin Microbiol 1984; 20: 962-965.

18 Alster Y, Herlin L, Lazar M, Loewenstein A. Intraocular penetration of vancomycin eye drops after application to the medial canthus with closed lids. Br J Ophthalmol 2000; 84: 300-302.

19 Smith MA, Sorenson JA, Smith C, Miller M, Borenstein M Effects of intravitreal dexamethasone on concentration of intravitreal vancomycin in experimental methicillinresistant Staphylococcus epidermidis endophthalmitis. Antimicrob Agents Chemother 1991; 35: 1298-1302.

20 Park SS, Vallar RV, Hong CH, von Gunten S, Ruoff K, D'Amico DJ. Intravitreal dexamethasone effect on intravitreal vancomycin elimination in endophthalmitis. Arch Ophthalmol 1999; 117: 1058-1062.

21 Blumenkranz MS, Claflin A, Hajek AS. Selection of therapeutic agents for intraocular proliferative disease. Cell culture evaluation. Arch Ophthalmol 1984; 102: 598-604.

22 Campochiaro PA, Lim JI. Aminoglycoside toxicity in the treatment of endophthalmitis. The Aminoglycoside Toxicity Study Group. Arch Ophthalmol 1994; 112: 48-53.

23 Donahue SP, Kowalski RP, Eller AW, DeVaro JM, Jewart BH. Empiric treatment of endophthalmitis. Are aminoglycosides necessary? Arch Ophthalmol 1994; 112: 45-47. 